\title{
Heat Shock Protein 70 (HSP70) Is Critical for the Photoreceptor Stress Response after Retinal Detachment via Modulating Anti-Apoptotic Akt Kinase
}

\author{
Maki Kayama, ${ }^{*}$ Toru Nakazawa, ${ }^{\text {}}{ }^{+}$ \\ Aristomenis Thanos, ${ }^{*}$ Yuki Morizane, ${ }^{*}$ \\ Yusuke Murakami, ${ }^{,}$Sofia Theodoropoulou, ${ }^{*}$ \\ Toshiaki Abe, ${ }^{\ddagger}$ Demetrios Vavvas, ${ }^{*}$ \\ and Joan W. Miller* \begin{abstract}
Eye and Ear Infirmary, and the Department of Ophthalmology, Harvard Medical School, Boston, Massachusetts; the Department of Ophthalmology, ${ }^{\dagger}$ Tohoku Graduate University School of Medicine, Miyagi, Japan; and the Division of Clinical Cell Therapy, ${ }^{\ddagger}$ Graduate School of Medicine, Tohoku University, Miyagi, Japan
\end{abstract} \\ From the Retina Service,* Angiogenesis Laboratory, Massachusetts
}

Photoreceptor apoptosis is a major cause of vision loss in many ocular diseases. Significant progress has been made to elucidate the molecular pathways involved in this process, yet little is known about proteins counteracting these apoptotic pathways. It is established that heat shock proteins (HSPs) function as molecular helper proteins (chaperones) by preventing protein aggregation and facilitating refolding of dysfunctional proteins, critical to the survival of all organisms. Here, we investigated the role of HSP70 on photoreceptor survival after experimental retinal detachment (RD) in mice and rats. We found that HSP70 was up-regulated after RD and associated with phosphorylated Akt, thereby preventing its dephosphorylation and further activation of cell death pathways. Administration of quercetin, which inhibits HSP70 and suppresses Akt phosphorylation significantly increased photoreceptor apoptosis. Similarly, RD-induced photoreceptor apoptosis was augmented in mice carrying hypomorphic mutations of the genes encoding HSP70. On the other hand, administration of geranylgeranylacetone, which induces an increase in HSP70 significantly decreased photoreceptor apoptosis after RD through prolonged activation of Akt pathway. Thus, HSP70 may be a favorable potential target to increase photoreceptor cell survival after RD. (Am J Pathol 2011, 178:1080-1091; DOI: 10.1016/j.ajpath.2010.11.072)
Retinal detachment (RD) occurs when the neural retina physically separates from the underlying retinal pigment epithelium and is a cause of permanent visual loss in a number of retinal disorders, including agerelated macular degeneration, ${ }^{1}$ diabetic retinopathy, ${ }^{2}$ and retinopathy of prematurity. ${ }^{3}$ Surgical repair has a success rate of more than $90 \%$ in reattaching the retina, ${ }^{4,5}$ however in cases where the macula is detached, only 20 to $40 \%$ of successful reattachments achieve visual acuity of $20 / 50$ or better. ${ }^{6}$

For the last decade, multiple lines of evidence have indicated that apoptosis is a major cause of photoreceptor loss in the rodent model of RD, as defined by the presence of pyknosis, apoptotic bodies, and internucleosomally cleaved DNA. ${ }^{--9}$ These results demonstrated the importance of both caspase-dependent and caspase-independent apoptotic pathways in RD-induced photoreceptor cell death. Despite this progress, the detailed mechanisms of photoreceptor cell death after RD remain fairly unclear, and little is known about counteracting pathways that promote photoreceptor survival.

Heat shock proteins (HSPs) are a family of stressactivated proteins that participate in protein folding and repair $^{10}$ and range in molecular weight from 10 to 170 $\mathrm{kDa}$. The $70 \mathrm{kDa}$ HSP (HSP70), one of the chaperones, plays a fundamental role in the protection of cells against

Supported by Grants-in-Aid from the Ministry of Education, Science, and Technology of Japan (21659395 and 22689045 to T.N.), Uehara Memorial Research Foundation, Takeda Research Foundation and Imai Glaucoma Research Foundation (T.N.), a Bausch \& Lomb Vitreoretinal Fellowship (M.K. and Y.M.), and National Eye Institute grant EY014104 (MEEl Core Grant).

Accepted for publication November 9, 2010.

Supplemental material for this article can be found at $h$ ttp://ajp. amjpathol.org or at doi:10.1016/j.ajpath.2010.11.072.

Address reprint requests to Joan W. Miller, M.D., Massachusetts Eye and Ear Infirmary, Harvard Medical School, 243 Charles St., Boston, MA 02114; or Toru Nakazawa, M.D., Ph.D., Department of Ophthalmology, Tohoku Graduate University School of Medicine, 1-1 Seiryo-machi, Aoba-ku, Sendai, Miyagi 980-8574, Japan. E-mail: joan_miller@ meei.harvard.edu or ntoru@oph.med.tohoku.ac.jp. 
stresses of various types and origins. When induced, HSP70 prevents the immediate apoptosis of cells and allows cellular adaptation, which is essential for cell survival. ${ }^{11-14}$ Others and ourselves have shown that apoptotic cell death is heavily involved in photoreceptor cell death after RD. ${ }^{7-9}$ In our study, we found a greater than $4 \times$ increase in HSP70 after RD and thus, we focused our attention to HSP70. A recent report has also showed that inducible HSP70 is a critical mediator of the phosphoinositide 3-kinase (PI3K)-Akt pathway, ${ }^{15}$ which is heavily involved in cellular survival and inhibition of apoptosis. ${ }^{16,17}$

Therefore, in this study we sought to investigate the potential role of HSP70 in the molecular events occurring after RD and to explore the possibility that HSP70 may act as a potential endogenous inhibitor of photoreceptor cell death after RD.

\section{Materials and Methods}

\section{Animals}

All animal experiments complied with the Association for Research in Vision and Ophthalmology for the use of animals in ophthalmic and vision research and were approved by the Animal Care and Use Committee of the Massachusetts Eye and Ear Infirmary (Boston, MA). Male Brown Norway rats (weighing $250 \mathrm{~g}$ ) were used in all experiments. Male (8 weeks old) $\mathrm{HSP}^{-1-}$ mice on C57BL/ 6x129S7 background were obtained from the University of California, Davis, and age- and sex-matched C57BL/6x129S7 mice were also used in the experiments. The animals were fed standard laboratory chow and allowed free access to water in an air-conditioned room with a 12-hour light/dark cycle. Except as noted otherwise, the animals were anesthetized with ketamine hydrochloride (30 $\mathrm{mg} / \mathrm{kg}$; Ketalar; Parke-Davis, Morris Plains, NJ) and xylazine hydrochloride (5 mg/kg; Rompun; Harver-Lockhart, Morris Plains, $\mathrm{NJ}$ ) before all experimental manipulations.

\section{Surgical Procedure of RD and Treatment with Quercetin and GGA}

After the induction of anesthesia, the pupils were dilated with a topically applied mixture of phenylephrine (5.0\%) and tropicamide (0.8\%). A sclerotomy was performed approximately 2-mm posterior to the limbus using a 30gauge needle, while tacking care not to damage the lens during the procedure. A Glaser subretinal injector (20gauge shaft with a 32-gauge tip) connected to a syringe filled with sodium hyaluronate was then introduced into the vitreous cavity. Retinotomy was performed in the peripheral retina with the tip of the subretinal injector, and sodium hyaluronate was slowly injected into the subretinal space, causing detachment of one-half of the retina. One hour before RD induction, $250 \mu$ l of quercetin (100 $\mathrm{mg} / \mathrm{ml}$, an HSP70 inhibitor) ${ }^{18,19}$ or vehicle (dimethyl sulfoxide) was injected intraperitoneally. In addition, $250 \mu$ l of geranylgeranylacetone (GGA) $(200 \mathrm{mg} / \mathrm{ml}$, an HSP70 inducer; a gift from Eisai Co, Ltd, Tokyo, Japan), ${ }^{18}$ with or without quercetin and vehicle (balanced salt solution) were injected intraperitoneally for 2 days before and 3 days after RD induction. At specified times after RD, the rats were sacrificed with an overdose of sodium pentobarbital, and the eyes were enucleated.

Table 1. Genes Differentially Expressed 72 Hours after RD

\begin{tabular}{cccl}
\hline Mean RD & Mean vehicle & RD/vehicle & \\
\hline 548.93 & 35.75 & 15.4 & Gene name \\
543.7 & 39.57 & 13.7 & Corneal wound healing-related protein \\
3570.83 & 275.05 & 13 & Crystallin, mu \\
903 & 161.82 & 5.6 & Solute carrier family 2 \\
1160.50 & 219.77 & 5.3 & ASI mRNA for mammalian equivalent of bacterial large ribosomal \\
& & & subunit protein L22 \\
1216.40 & 242 & 5 & Aminopeptidase B (Rnpep) \\
1511.93 & 311.15 & 4.9 & Human 40S ribosomal protein S18 \\
1043.43 & 210.9 & 4.9 & Ribosomal protein L27 \\
998.77 & 203.85 & 4.9 & Elongation factor 1 alpha \\
680.2 & 139.25 & 4.9 & Protein tyrosine phosphatase 4a3 (Mus musculus) \\
1283.17 & 267.98 & 4.8 & Ribosomal protein L \\
4287.20 & 917.05 & 4.7 & Fudenine (mouse prominin) retinal degeneration \\
1726.87 & 368.55 & 4.7 & Transforming growth factor beta stimulated clone 22 \\
619.3 & 130.65 & & Rat unidentified mRNA expressed in embryo and tumor but not \\
& & normal differentiated cells \\
1000.17 & 217.2 & 4.6 & H2A histone family, member Z \\
757.2 & 162.88 & 4.6 & Anti-proliferative (Btg1) \\
686.13 & 148.62 & 4.6 & Rattus norvegicus ribosomal protein L6 \\
642.6 & 140.2 & 4.6 & Carnitine O-octanoyltransferase \\
1305.43 & 288.32 & 4.5 & KPL1 \\
1405.27 & 321.92 & 4.4 & 60S Ribosomal protein L37A \\
530.77 & 123.4 & 4.3 & (Hsp40) Homolog \\
1106.93 & 263.05 & 4.2 & Double-stranded RNA-binding protein p74 \\
1583.43 & 387.6 & Ribosomal protein S14 (Rps14) \\
627.1 & 153.45 & Casein kinase I delta \\
581.8 & 141.73 & 60S Acidic ribosomal protein P1 \\
538.27 & 131.92 & Heat shock protein 70 kD \\
\hline
\end{tabular}

$R D$, retinal detachment. 


\section{Laser-Capture Microdissection}

To investigate gene expression patterns in $\mathrm{RD}$, laser-capture microdissection (LCM) was performed in 4 rats as previously described. ${ }^{20}$ This technique allows the capture of specific cells in a histological section using laser irradiation. ${ }^{21}$ Briefly, 72 hours after RD, the eyes were enucleated and embedded in Tissue Tek Optimal Cutting Temperature Compound (Sakura Finetechnical, Tokyo, Japan). Sections (12 um) were cut with a cryostat (Micron, Walldorf, Germany) and mounted on Superfrost Plus glass slides (Fisherbrand, Pittsburgh, PA). Tissue sections were rehydrated with $75 \%$ ethanol, twice with diethylpyrocarbonate water, followed by dehydration with $75 \%, 95 \%$, and $100 \%$ ethanol for 1 minute each, and xylene for 5 minutes. For cells of the outer nuclear layer (ONL), LCM was carried out at $90 \mathrm{~mW}$ for 1.2 seconds and a spot size of $15 \mu \mathrm{m}$. All of these samples were used for a DNA microarray approach.

\section{Microarray Analysis}

Total RNA was purified using RNeasy Kit (Qiagen, Valencia, CA). Biotin-tagged cDNA was synthesized, used to probe custom-printed oligo-arrays via hybridization for 12 to 16 hours (SuperArray Bioscience Corp, Frederick, $\mathrm{MD}$ ), and subsequently imaged using chemiluminescent detection in combination with X-ray film detection (Kodak, Tokyo, Japan). Scanned films were imported to the webbased software (GEarray Suite version 2.0; SABiosciences, Frederick, MD); the online software was discontinued for analysis on December 31, 2010. Each array included a set of internal housekeeping genes to adjust and correct for loading. Qualitative absent/present values were evaluated based on 10-minute exposures. A signal that was visually above the background was defined as present. Quantification was assessed using averaged values obtained from the web-based SuperArray software and $t$-tests were performed using GraphPad Prism, version 4 (GraphPad Software, La Jolla, CA).

\section{Western Blotting}

For immunoblot detection of HSP70, Akt, and phosphorylated Akt (pAkt), we used a total of 32 animals (64 retinas), four for each treatment and control group. Whole retinas were harvested and lysed for 30 minutes on ice in lysis buffer [50 mmol/L Tris-HCl (lsqb)pH 8(rsqb), with $120 \mathrm{mmol} / \mathrm{L} \mathrm{NaCl}$ and 1\% Nonidet P-40], supplemented with a mixture of proteinase inhibitors (Complete Mini; Roche Diagnostics, Basel, Switzerland). The samples were centrifuged $\left(14,000\right.$ rpm for 30 minutes at $\left.4^{\circ} \mathrm{C}\right)$ and supernatants were collected. Protein concentration was assessed with Bicinchoninic acid protein assay (Pierce, Rockford, IL). Thirty mcg of protein per sample were separated in a $4 \%$ to $20 \%$ gradient sodium dodecyl sulfatepolyacrylamide gel (Invitrogen Corp, Carlsbad, CA) electrophoresis, and the proteins were electroblotted onto polyvinylidene difluoride membranes. After 20 minutes incubation in blocking solution (Starting Block T20; Thermo Scientific, Whaltham, MA), membranes were incubated with primary antibodies overnight at $4^{\circ} \mathrm{C}$. Peroxidase-labeled secondary antibodies (Amersham Pharmacia Biotech, Piscataway, NJ) were used, and proteins were visualized with enhanced chemiluminescence technique (Amersham Pharmacia Biotech).
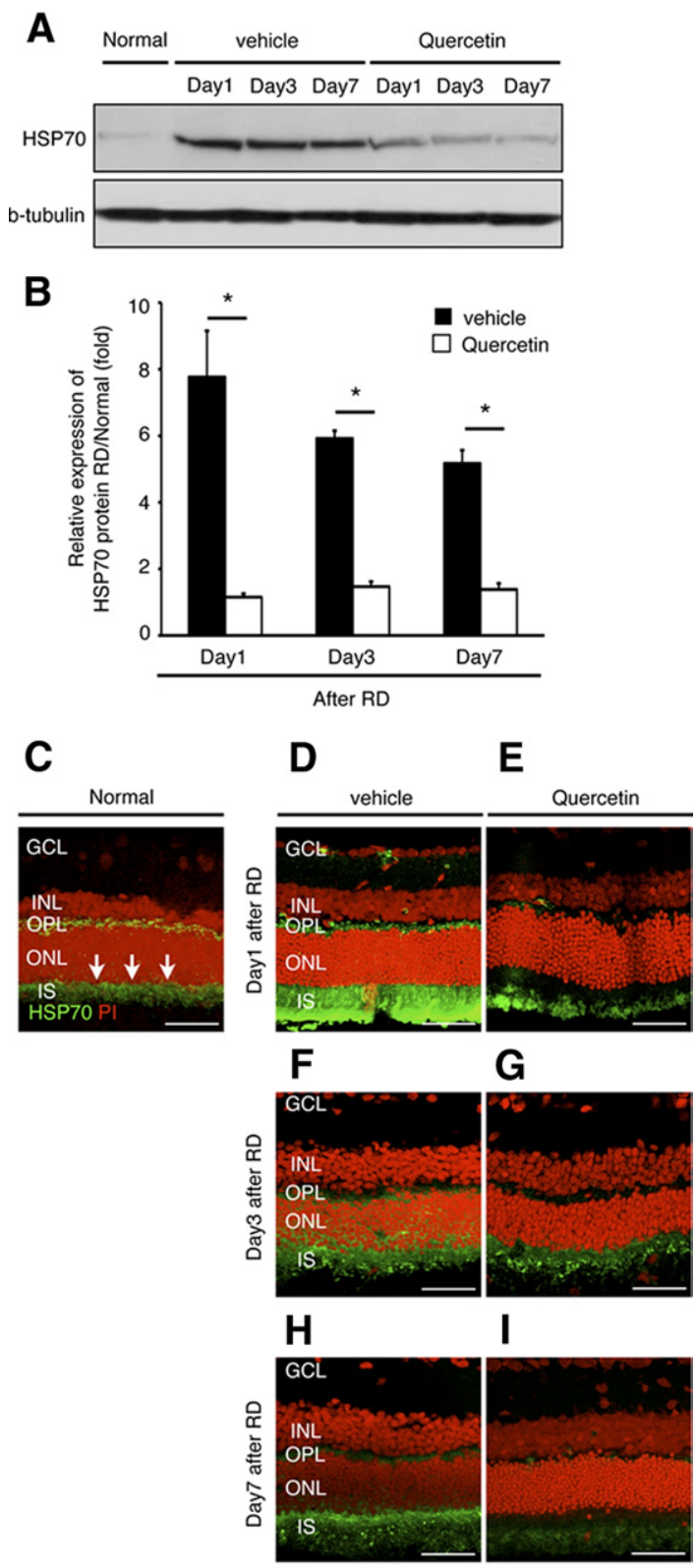

Figure 1. Efficiency of quercetin for HSP70. A and B: Western blot analysis for HSP70. A: Western blot analyses show the dynamics of protein expression of HSP70 in each group. B: Relative protein expression ratio of HSP70 at 1 , 3 , and 7 days after retinal detachment (RD) in each group. The protein expression level of HSP70 was normalized by the normal group. In the quercetin group, the expression was already diminished at day 1 (A and $\mathbf{B}$ ) $\left({ }^{*} P<0.01\right)$. Equal quantities of protein were loaded in all lanes, and representative exposures of enhanced chemiluminescence detection of the immunoreactive proteins are shown. Each column represents the mean $\pm \mathrm{SD}$ of four independent experiments. C-I: Immunofluorescent analysis for HSP70. In the normal group, expression of HSP70 was faintly seen in the outer plexiform layer and inner segment (IS) (arrows). In contrast, in the IS of the vehicle group showed dense expression of HSP70. In the quercetin group, expression of HSP70 was similar to normal. Scale bars $(\mathbf{C}-\mathbf{I})=$ $50 \mathrm{um}$. GCL, retinal ganglion cell layer; INL, inner nuclear layer; ONL, outer nuclear layer; OPL, outer plexiform layer. 


\section{Immunohistochemistry}

Immunohistochemistry was performed as previously reported. ${ }^{22}$ After fixation and permeabilization, the sections were incubated with one of the following primary antibodies: anti-HSP70 (Stressgen, 1:150), anti-pAkt (Stressgen, 1:50), anti-caspase-9 (Cell signaling, 1:300), or anticaspase-3 (Cell signaling, 1:300). An appropriate fluorophore-conjugated secondary antibody (Molecular Probes, Carlsbad, CA) was used to detect fluorescence using a confocal microscope (Leica Microsystems, Wetzler, Germany).

\section{Immunoprecipitation Western Analysis}

At various time points after $\mathrm{RD}(\mathrm{n}=4)$, eyes from quercetin or the vehicle-treated group were extracted, and the retinas were incubated in cell lysis buffer on ice for 30 minutes. Five hundred mcg of total protein were mixed with anti-pAkt antibody (Stressgen) and incubated overnight at $4^{\circ} \mathrm{C}$. Protein G-Agarose beads (Thermo Scientific) were added, and the mixture was incubated for another 2 hours at $4^{\circ} \mathrm{C}$. Immune complexes were washed 5 times with cold lysis buffer and denatured by boiling them for 5 minutes in sodium dodecyl sulfate buffer. Sodium dodecyl sulfate-polyacrylamide gel and difluoride membrane transfer were performed as previously described.

\section{Measurement of Caspase-9 and -3}

The activities of caspase- 9 and -3 were measured with the use of a commercially available kit according to the manufacturer's instructions (APT131/139; Millipore, Billerica, MA). At each time point, activities in the detached retina treated with vehicle, quercetin, and/or GGA were normalized to their corresponding activities in the attached retina at the same time point.

\section{TUNEL Analysis}

Terminal deoxynucleotidyl transferase-mediated dUTP nick-end labeling (TUNEL) and quantification of TUNEL (+) cells were performed as previously described ${ }^{20}$ by using the ApopTag Fluorescein in situ Apoptosis Detection Kit (S7110; Chemicon International, Temecula, CA). The center of the detached retina was photographed, and the number of TUNEL $(+)$ cells in the ONL was counted in a masked fashion. The ONL thickness was measured with OpenLab software (Open Lab, Florence, Italy).

\section{Statistical Analysis}

The data are expressed as mean \pm SD mean data among groups were compared with one-way analysis of variance, and data between groups were compared with the unpaired Student's t-test. Statistical significance was declared for $P<0.05$. Two-tailed tests were used for all comparisons.

\section{Results}

\section{$R D$-Induced Changes in Gene Expressions}

To identify changes in expression levels of proteins after $\mathrm{RD}$, we used the established methods of LCM. We per-
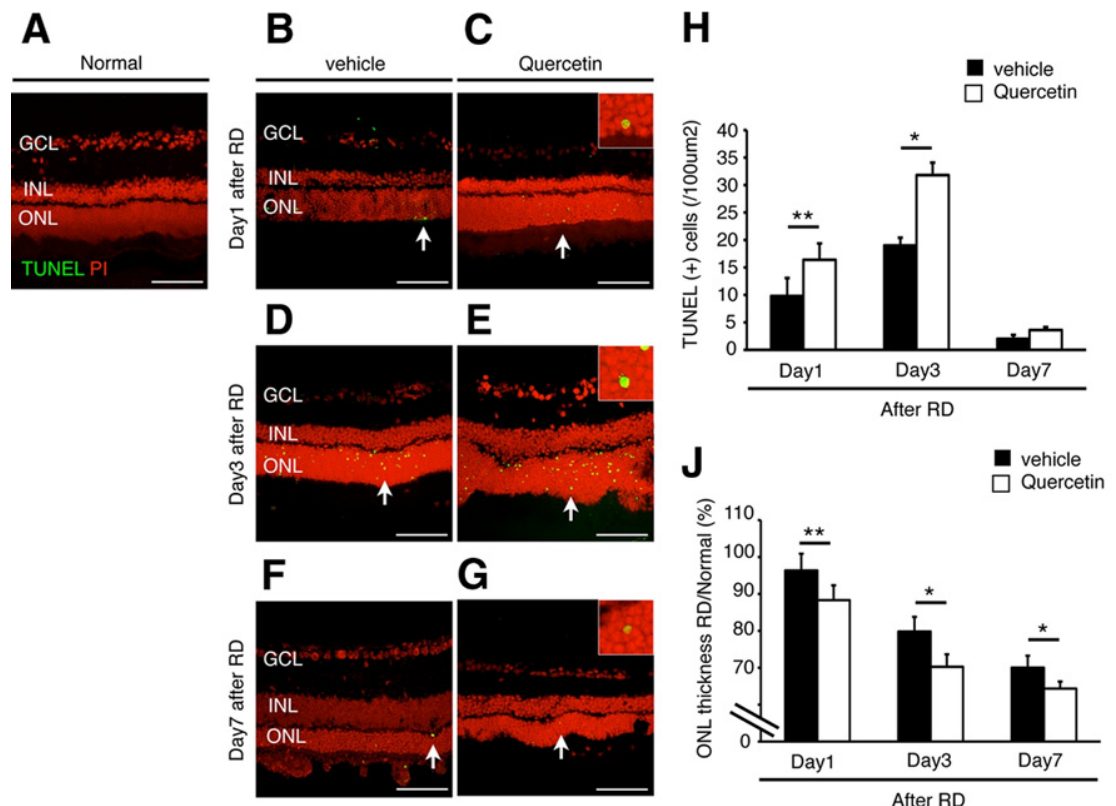

I

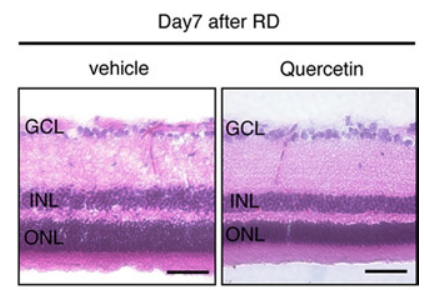

Figure 2. Quercetin-induced photoreceptor apoptosis 3 days after retinal detachment (RD). A-G: Transferase-mediated dUTP nick-end labeling (TUNEL) assay in the normal (A), vehicle (B, D, and $\mathbf{F})$ and quercetin $(\mathbf{C}, \mathbf{E}$, and $\mathbf{G})$ at 1,3 , and 7 days after RD. TUNEL $(+)$ cells $($ arrows $)$ were observed in the outer nuclear layer $(\mathrm{ONL})(\mathbf{C}, \mathbf{E}$, and $\mathbf{G})$. Insets are higher magnification of arrows at panel $\mathbf{C}, \mathbf{E}$, and $\mathbf{G})$. H: Quantification of TUNEL (+) cells by immunohistochemistry. Note that the number of TUNEL $(+)$ cells was significantly lower in the vehicle than in the quercetin $\left({ }^{*} P<0.01 ;{ }^{* * *} P<0.05\right)$. I: Representative photomicrographs of RD at 7 days. J: Relative ratio of the ONL thickness in each group. In the both groups, ONL thickness was decreased with time. However, ONL thickness in the quercetin group was significantly decreased compared with the vehicle group of them $\left({ }^{*} P<0.01\right.$, $\left.{ }^{* *} P<0.05\right)$. Each column represents the mean $\pm \mathrm{SD}$ of four independent experiments. Scale bars $(\mathbf{A}-\mathbf{G}, \mathbf{I})=100 \mathrm{um}$. GCL, retinal ganglion cell layer; INL, inner nuclear layer. 
formed this study 3 days after RD induction, when photoreceptor cell loss reaches its peak as shown in our previous study. ${ }^{7,8}$ Cells from the ONL were collected by LCM (see Supplemental Figure S1 at http://ajp.amjpathol.org) and a microarray screen was conducted to identify genes potentially involved in the resolution of $\mathrm{RD}$ and recovery of function. We used gene chips [MOE_430A GeneChips; Affymetrix, Santa Clara, CA] to evaluate the expression levels of more than 22,000 probe sets in several biological replicates of normal (attached) or detached retinas during this study. After microarray hybridization, analysis, and data normalization, we identified genes showing a microarray fold change of $\geq 2.3$ between normal retina and RD samples. We detected 150 genes that demonstrated differential expression between attached and detached retinas (Table 1). Of these, a 4.1-fold up-regulation of HSP70 was observed in the RD group. Therefore, we sought to further characterize the role of HSP70 in RD.

\section{HSP70 Expression Is Up-Regulated after RD}

To confirm the change of HSP70 at protein level we performed Western blot analysis at 1, 3 and 7 days after RD (Figure 1A). In the vehicle-treated group, we observed a 7.8-fold increase in HSP70 (70 kDa) protein levels compared to attached retina that subsequently decreased with time (Figure 1B). Administration of quercetin, a potent HSP inhibitor, suppressed HSP70 protein level at all studied time points (Figure 1B) (vehicle: day 3, 5.9-fold; day 7, 5.2-fold and quercetin: day 1, 1.2-fold; day 3, 1.5-fold; day 7, 1.4fold). To further determine the distribution pattern of HSP70 protein within the retina, we performed immunohistochemistry on frozen sections obtained at 1, 3, and 7 days after RD. Consistent with a previous study, ${ }^{23}$ expression of HSP70 was faintly observed in the outer plexiform layer and inner segment in the attached retina (Figure 1C). However, retinal detachment resulted in strong HSP70 immunoreactivity in the outer plexiform layer and inner segment (Figure $1, D, F$, and $H$ ), which was significantly decreased after quercetin administration (Figure 1, E, G, and I).

\section{Quercetin Administration Increases Photoreceptor Apoptosis after RD}

Next, we investigated the effect of HSP70 down-regulation by quercetin in experimental RD. To this aim, we used TUNEL assay and evaluated the ONL thickness in rats pretreated with vehicle or quercetin 1 hour before RD
A
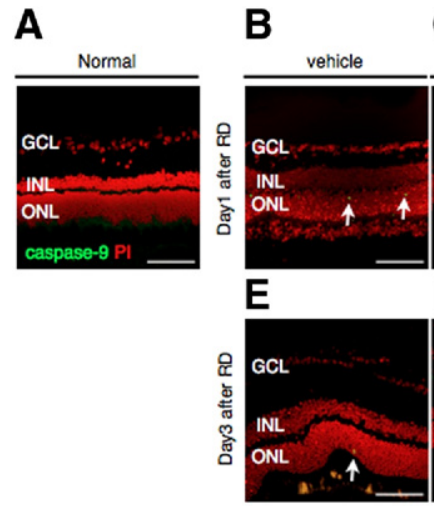

$\mathbf{K}$

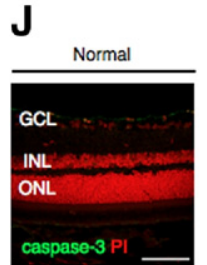

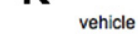

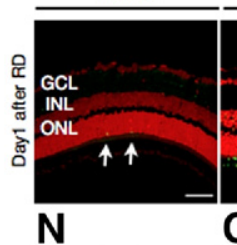

C

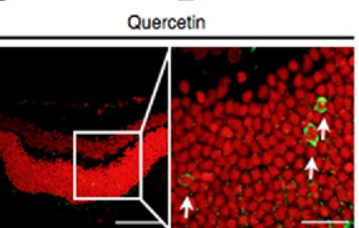

$\mathbf{F}$

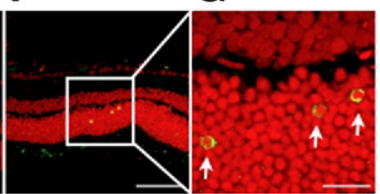

L

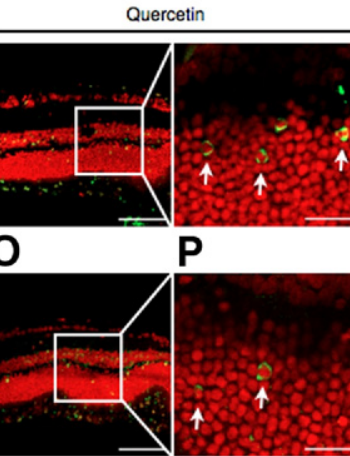

H
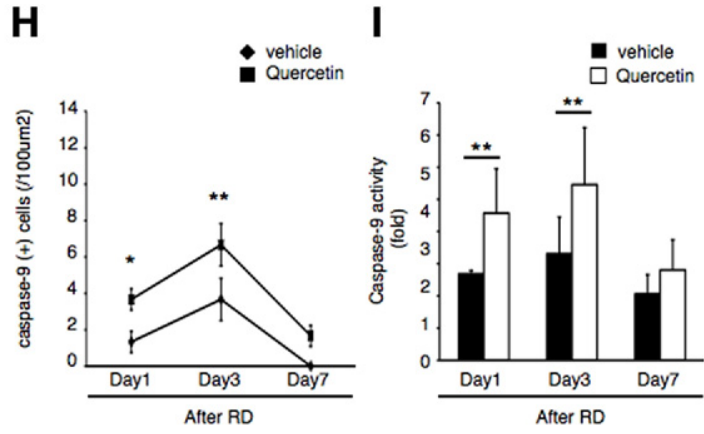

Q

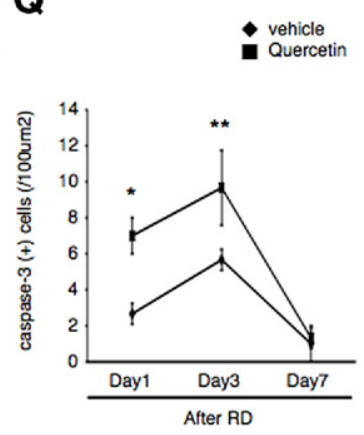

$\mathbf{R}$
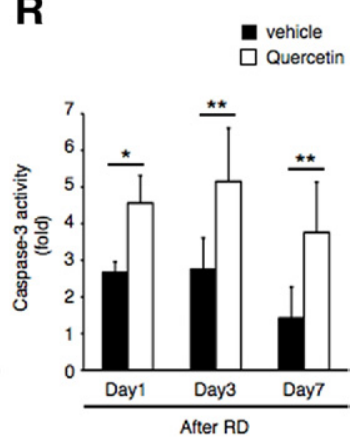

Figure 3. Quercetin up-regulated cleaved caspases-9 and -3. A-G: Immunofluorescent analysis for cleaved caspase-9 in each group 1 and 3 days after retinal detachment (RD). In the normal, cleaved caspase-9 $(+)$ cells were not seen $(\mathbf{A})$. In the vehicle $(\mathbf{B}$ and $\mathbf{E})$ and quercetin $(\mathbf{C}, \mathbf{D}, \mathbf{F}$, and $\mathbf{G})$ groups, cleaved caspase- 9 $(+)$ cells (arrows) were observed in the outer nuclear layer (ONL). Notably, cleaved caspase-9 $(+)$ cells were expressed in the cytoplasm and confirmed in the ONL. D and G: Higher magnification of inset of $\mathbf{C}$ and $\mathbf{F}$. J-P: Immunofluorescent analysis for cleaved caspase-3 in each group 3 days after RD. In the normal, cleaved caspase-3 $(+)$ cells were not seen $(\mathbf{J})$. In the vehicle $(\mathbf{K}$ and $\mathbf{N})$ and quercetin $(\mathbf{L}, \mathbf{M}, \mathbf{O}$, and $\mathbf{P})$ groups, cleaved caspase-3 $(+)$ cells $($ arrows $)$ were observed in the ONL. Cytosolic staining of cleaved caspase-3 was observed in the ONL ( $\mathbf{M}$ and $\mathbf{P}$ ): Higher magnification of inset of $\mathbf{L}$ and $\mathbf{O}$. H: Quantification of cleaved caspase- $9(+)$ cells by immunohistochemistry. Increased activity of cleaved casapase- 9 induced by quercetin $\left({ }^{*} P<0.01\right.$, $\left.{ }^{* *} P<0.05\right)$. I: Increased of caspase-9 activity after RD by the injection of quercetin at the time point of RD $\left({ }^{* *} P<0.05\right)$. Q: Quantification of cleaved caspase-3 $(+)$ cells by immunohistochemistry. Increased activity of cleaved casapase-3 induced by quercetin $\left({ }^{*} P<0.01\right.$; $\left.{ }^{* * *} P<0.05\right)$. R: Increased of caspase-3 activity after RD by the injection of quercetin at the time point of RD $\left({ }^{*} P<0.01 ;{ }^{* *} P<0.05\right)$. Each point represents the mean \pm SD of four independent experiments. Scale bars $(\mathbf{A}-\mathbf{C}, \mathbf{E}, \mathbf{F}, \mathbf{J}-\mathbf{L}, \mathbf{N}, \mathbf{O})=100$ um, and $(\mathbf{D}, \mathbf{G}, \mathbf{M}$, and $\mathbf{P})=50 \mathrm{um}$. GCL, retinal ganglion cell layer; INL, inner nuclear layer. 
induction. We detected TUNEL $(+)$ apoptotic photoreceptors at 1, 3, and 7 days after RD in the ONL (Figure 2, B-G). In line with previous reports, $8,24,25$ we observed maximal photoreceptor cell apoptosis on day 3 after RD (Figure $2 \mathrm{H}$ ). Significantly more TUNEL $(+)$ cells were counted in the quercetin-treated group compared to vehicle (Figure $2 \mathrm{H}$ ). No TUNEL (+) cells were detected in normal attached retina (Figure 2A). By day 7 after RD, the ONL thickness in the quercetin group has significantly declined compared to vehicle treatment (Figure 2, I and J). Taken together, these data indicate that HSP70 downregulation by quercetin increases photoreceptor apoptosis and accelerates retinal degeneration after RD.

\section{Down-Regulation of HSP70 by Quercetin Results in Increased Caspase Activation}

We have previously reported the major role of caspase activation in photoreceptor cell death after RD. ${ }^{8}$ Caspases execute the classical apoptosis program. ${ }^{26}$ Release of cytochrome-c from the mitochondria results in the formation of the apoptosome, the recruitment and activation of pro-caspase-9, which further activates caspase-3. ${ }^{27}$ To investigate the level of caspase- 9 and -3 activation after quercetin or vehicle treatment, we performed immunohistochemistry and activity assays at various time points after RD induction. In our experiments, maximal activation of caspases- 9 and -3 was observed on day 3 (Figure $3, \mathrm{H}, \mathrm{I}, \mathrm{Q}$, and R). Quercetin administration increased the number of caspase-9 and $-3(+)$ cells as detected with immunohistochemistry (Figure 3, $\mathrm{C}, \mathrm{D}, \mathrm{F}-\mathrm{H}, \mathrm{L}, \mathrm{M}$, and $\mathrm{O}-\mathrm{Q}$ ), as well as their respective activities compared to vehicle treatment (Figure 3, B, E, I, $\mathrm{K}, \mathrm{N}$, and R). Furthermore, cleaved caspases- 9 and -3 co-localized with TUNEL $(+)$ photoreceptors (see Supplemental Figure S2 at $h$ ttp://ajp.amjpathol.org). We did not detect any cleaved caspase- 9 or -3 in the attached retina (Figure $3, \mathrm{~A}$ and $\mathrm{J}$ ). Collectively, these data indicate that HSP70 down-regulation by quercetin increases caspase- 9 and -3 activities after RD.

\section{HSP70 Deficiency Augments Photoreceptor Cell Apoptosis}

To further elucidate the role of HSP70 in photoreceptor apoptosis, we induced RD in HSP70 deficient $\left(\mathrm{HSP} 70^{-1-}\right)$ mice. Histologic evaluation of the retina between $\mathrm{HSP}^{-1} \mathrm{O}^{-1-}$ mice and their respective wild-type controls did not reveal any abnormalities (see Supplemental Figure S3 at http://ajp.amjpathol.org). However, on RD induction the number of TUNEL (+) photoreceptors increased dramatically in the HSP70 ${ }^{-1-}$ group in contrast with the wild-type group (Figure 4, A-G). Interestingly, TUNEL $(+)$ cells were also detected in the inner nuclear layer and retinal ganglion cell layer of $\mathrm{HSP}^{-1-}$ mice. By 7 days after RD, the ONL thickness in the $\mathrm{HSP}^{-1-}$ group was significantly reduced with respect to control (Figure 4H). As expected, immunohistochemical staining showed an increase in cleaved caspase-9 and $-3(+)$ cells in the $\mathrm{HSP}^{-1-}$ mice group in contrast with wild-
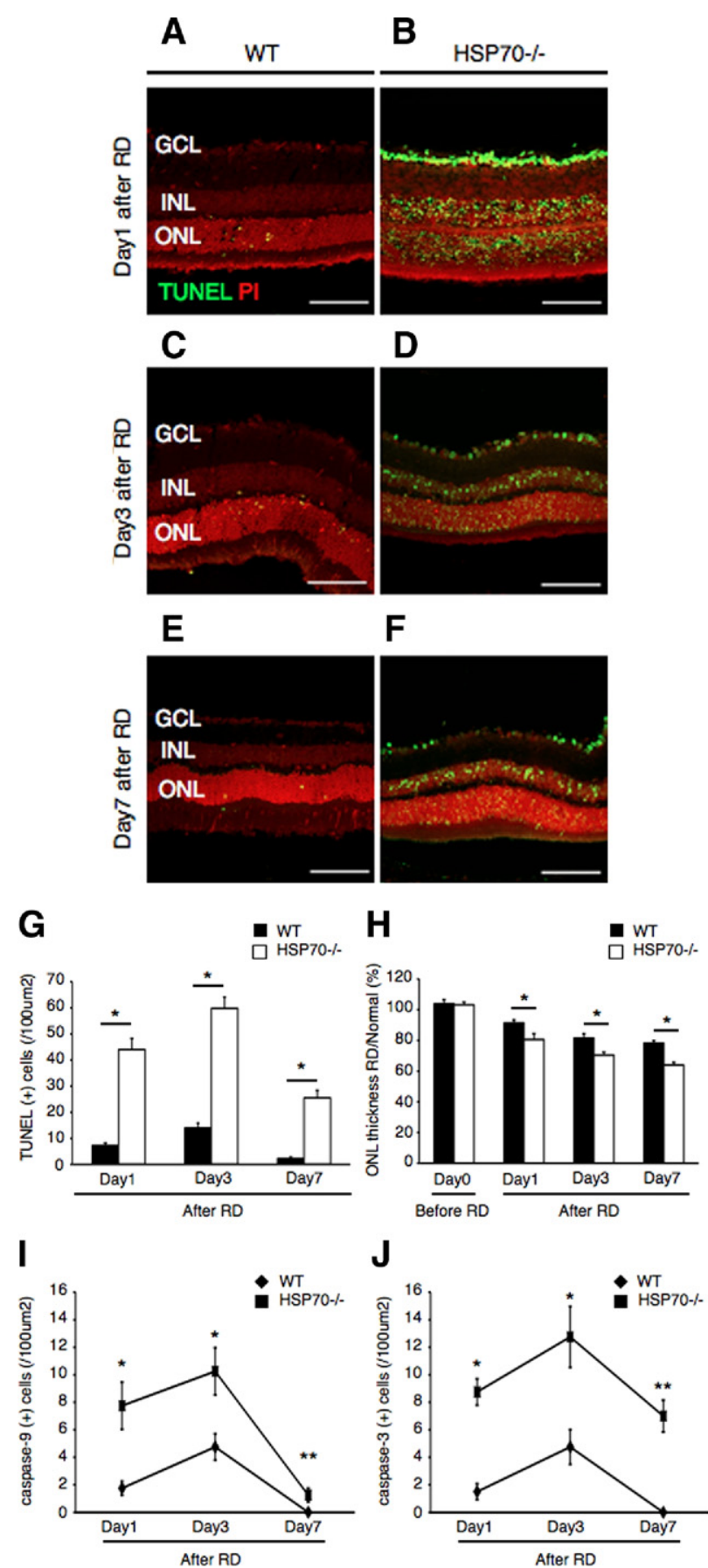

$\mathbf{J}$

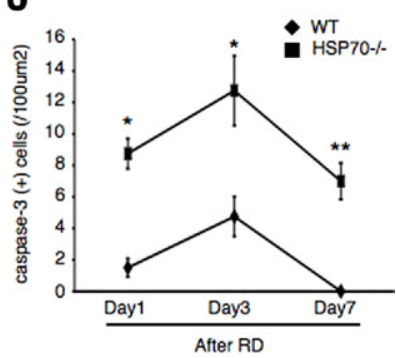

Figure 4. Photoreceptor apoptosis up-regulated in the $\mathrm{HSP}^{-1-}$ mice after retinal detachment (RD). A-F: Transferase-mediated dUTP nick-end labeling (TUNEL) assay in the wild-type (WT) mice $(\mathbf{A}, \mathbf{C}, \mathbf{E})$ and $\mathrm{HSP} 70^{-/-}$mice $(\mathbf{B}$, D, F) 1,3 , and 7 days after RD. TUNEL $(+)$ cells were mainly observed in the outer nuclear layer (ONL). G: Quantification of TUNEL $(+)$ cells by immunohistochemistry. Note that the number of TUNEL $(+)$ cells was significantly lower in the WT mice group than in the $\mathrm{HSP}^{-1-}$ mice group $\left({ }^{*} P<0.01\right)$. H: Relative ratio of the outer nuclear layer (ONL) thickness in each group. In both groups, the ONL thickness was decreased with time. However, the ONL thickness in the $\mathrm{HSP} 70^{-/-}$mice group was significantly decreased compared with the WT mice group of them $\left({ }^{*} P<0.01\right)$. I: Quantification of cleaved caspase- $9(+)$ cells by immunohistochemistry. Cleaved casapase-9 $(+)$ cells increased in the HSP70 ${ }^{-1-}$ mice group $\left(^{*} P<\right.$ $\left.0.01 ;{ }^{* *} P<0.05\right)$. J: Quantification of cleaved caspase-3 $(+)$ cells by immunohistochemistry. Cleaved casapase- $3(+)$ cells increased in the HSP70 ${ }^{-1}$ mice group $\left({ }^{*} P<0.01\right)$. Each column represents the mean $\pm \mathrm{SD}$ of six independent experiments. Scale bars $=100 \mathrm{um}$. GCL, retinal ganglion cell layer; INL, inner nuclear layer. 
A
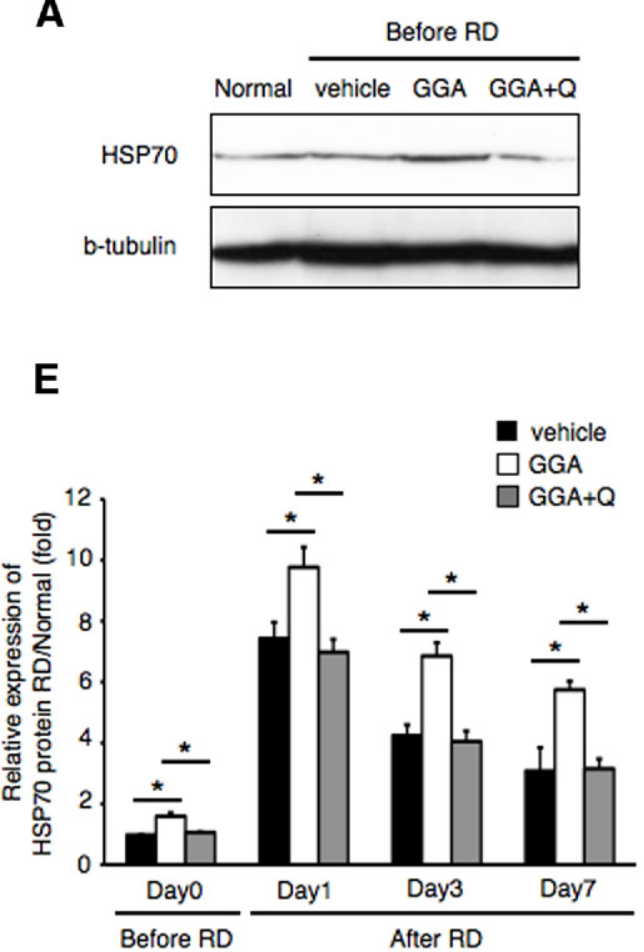
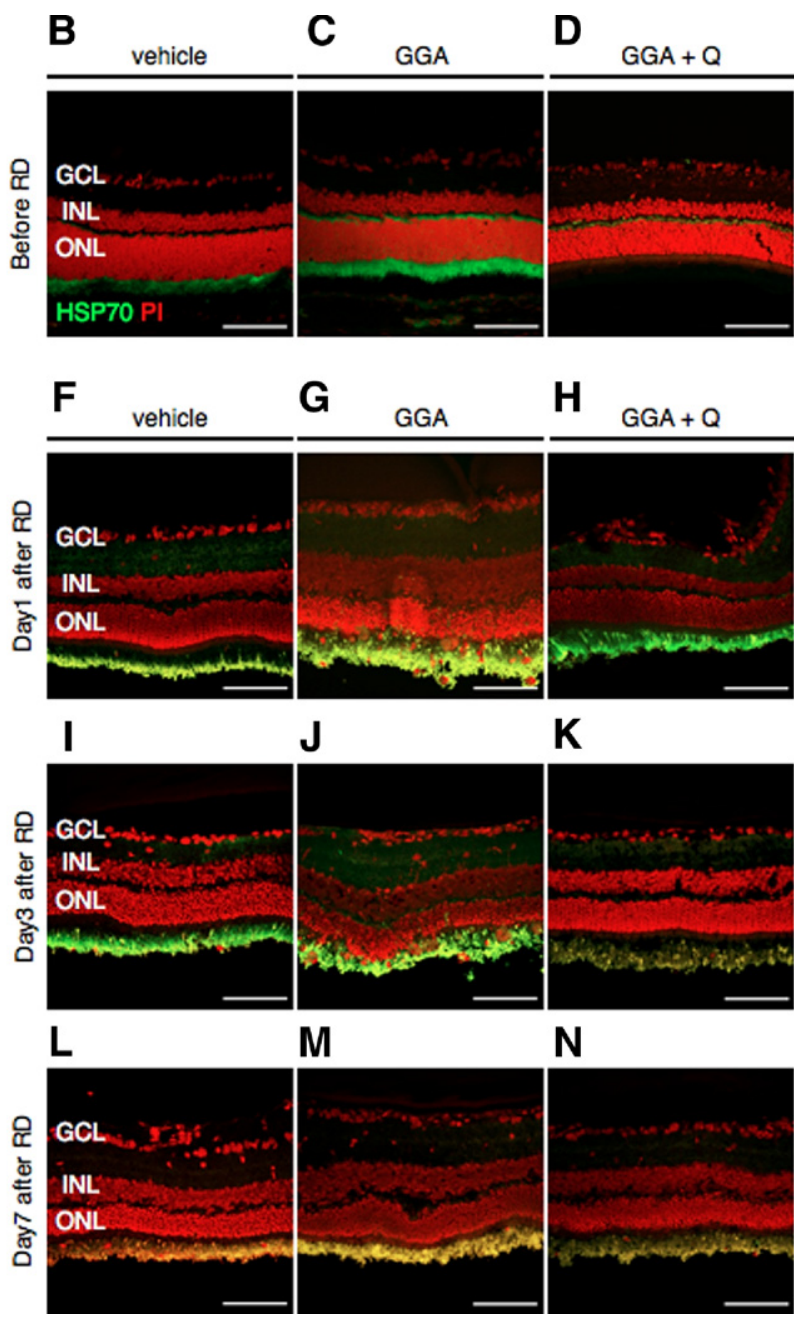

Figure 5. Induction of HSP70 after administration of geranylgeranylacetone (GGA). A: Western blot analysis showed increased HSP70 protein level in the attached retina with GGA administration. There was no change in the HSP70 protein level after administration of GGA with quercetin and vehicle. B-D, F-N: Immunofluorescent analysis for HSP70. In the vehicle, expression of HSP70 was faintly seen in the inner segment (IS). In contrast, the IS of the GGA group showed dense expression of HSP70. In the GGA with quercetin group, expression of HSP70 was similar to vehicle. E: Relative protein expression ratio of HSP70 at 0,1 , 3 , and 7 days after retinal detachment (RD) in each group. The protein expression level of HSP70 was normalized by the normal group. In the GGA group, the expression was already up-regulated before RD $\left({ }^{*} P<0.01\right)$. Equal quantities of protein were loaded in all lanes, and representative exposures of enhanced chemiluminescence detection of the immunoreactive proteins are shown. Each column represents the mean \pm SD of six independent experiments. Scale bars $=$ 100 um. GCL, retinal ganglion cell layer; INL, inner nuclear layer; ONL, outer nuclear layer; Q, quercetin.

type mice group (Figure 4, I and J). These results provide direct evidence that HSP70 plays a critical role in counteracting RD-induced photoreceptor apoptosis.

\section{Administration of GGA Up-Regulates Retinal HSP70 Expression Levels}

GGA is known to induce an increase expression of HSP70, but not HSP60 and HSP90, in a variety of cells and tissues. ${ }^{28-30}$ To confirm whether administration of GGA induces HSP70 expression in the rat retina, we performed immunoblot analysis and immunohistochemistry. Indeed, GGA treatment resulted in significant increase in HSP70 protein expression (Figure 5A) and immunoreactivity, which was confined to the inner segment/ outer limiting membrane of photoreceptors (Figure 5, B-D). Coadministration of quercetin with GGA completely reversed this effect (Figure 5, A and D). Similar results were obtained on RD induction. Notably, pretreatment of animals with GGA potentiated HSP70 protein expression levels that remained elevated up to 7 days after $\mathrm{RD}$ (Figure 5E). These results were further confirmed with immunohistochemistry (Figure 5, G, J, and M). Quercetin coadministration with GGA blocked the effects of GGA in increasing HSP70 protein expression (Figure 5, H, K, and $\mathrm{N}$ ), similar to vehicle (Figure 5, F, I, and L). Thus, GGA administration resulted in significant up-regulation of HSP70 within the inner segment and the outer limiting membrane.

\section{HSP70 Overexpression by GGA Suppresses Photoreceptor Apoptosis after RD}

To examine whether HSP70 overexpression by GGA was able to reduce photoreceptor apoptosis after $\mathrm{RD}$, we performed TUNEL assay and evaluated the ONL thick- 
ness along with caspase activity assay in rats treated with vehicle, GGA, or GGA with quercetin. No TUNEL (+) cells were detected in attached retinas of all 3 groups (Figure 6, A-C). However, after RD induction, we detected TUNEL (+) apoptotic photoreceptors at 1, 3, and 7 days after RD in the ONL (Figure 6, D-L). GGA administration resulted in more than $50 \%$ decrease of TUNEL $(+)$ cells compared to the other groups, and preserved the ONL thickness as measured at 7 days after RD (Figure 6, M and $N$ ). In addition, GGA treatment decreased both caspase- 9 and -3 activities in contrast with the other two groups (Figure 6, $\mathrm{O}$ and $\mathrm{P}$ ). These results suggested the HSP70 overexpression by GGA ameliorates photoreceptor apoptosis after RD through down-regulation of caspase- 9 and -3 activities.

\section{Activation of Akt Kinase after Experimental RD}

Next, we sought to investigate the underlying mechanism for the neuroprotective role of HSP70 overexpression after $\mathrm{RD}$. It has been recently reported that inducible HSP70 regulates the activity of Akt kinase. ${ }^{15}$ Akt is a key component of cell survival pathways and a major downstream target of PI3K, which has been shown to mediate growth factor-induced neuronal survival stimuli. In addition, Akt kinase activation has been reported to inhibit caspase- 9 activity by direct phosphorylation. ${ }^{31}$ At first we asked whether Akt kinase is activated after RD. To this aim, we performed immunoblot analysis at 1, 3, and 7 days after $\mathrm{RD}$ using an antibody recognizing the phosphorylated form of Akt (pAkt). In the vehicle-treated group, we observed a 2.3-fold increase of Akt phosphorylation by day 1 that decreased thereafter in a timedependent manner (Figure 7, A and D). Quercetin administration resulted in a decrease in the phosphorylation status of Akt at all time points studied (Figure 7, A and D). On the other hand, GGA treatment markedly amplified Akt phosphorylation levels, whereas coadministration of GGA with quercetin abolished this effect (Figure 7, B and E). Finally $\mathrm{HSP} 70^{-1-}$ mice, exhibited decreased levels of Akt phosphorylation after RD induction compared to wildtype controls (Figure 7, C and F).

To further investigate the localization of pAkt within the detached retina, we performed immunohistochemistry on frozen sections obtained at 1 and 3 days after RD. pAkt immunostaining was predominantly identified in the photoreceptor nuclei, ${ }^{32}$ as well as faintly in the retinal ganglion cell layer and inner nuclear layer (Figure 7, $\mathrm{H}$ and M). GGA administration resulted in increase in pAkt immunoreactivity both at 1 and 3 days after RD (Figure 7, J and $O$ ), which was attenuated with quercetin coadministration (Figure 7, K and $\mathrm{P}$ ). In the quercetin-treated group and $\mathrm{HSP}^{-1-}$ group, faint immunostaining was observed in the retinal ganglion cell layer, but not in the ONL (Figure 7, I, L, N, and Q). We did not detect any expression of pAkt in the attached retina (Figure 7G). Collectively, these data indicate that Akt kinase is markedly activated in photoreceptors after RD and overexpression of HSP70 by GGA administration prolongs pAkt activation.
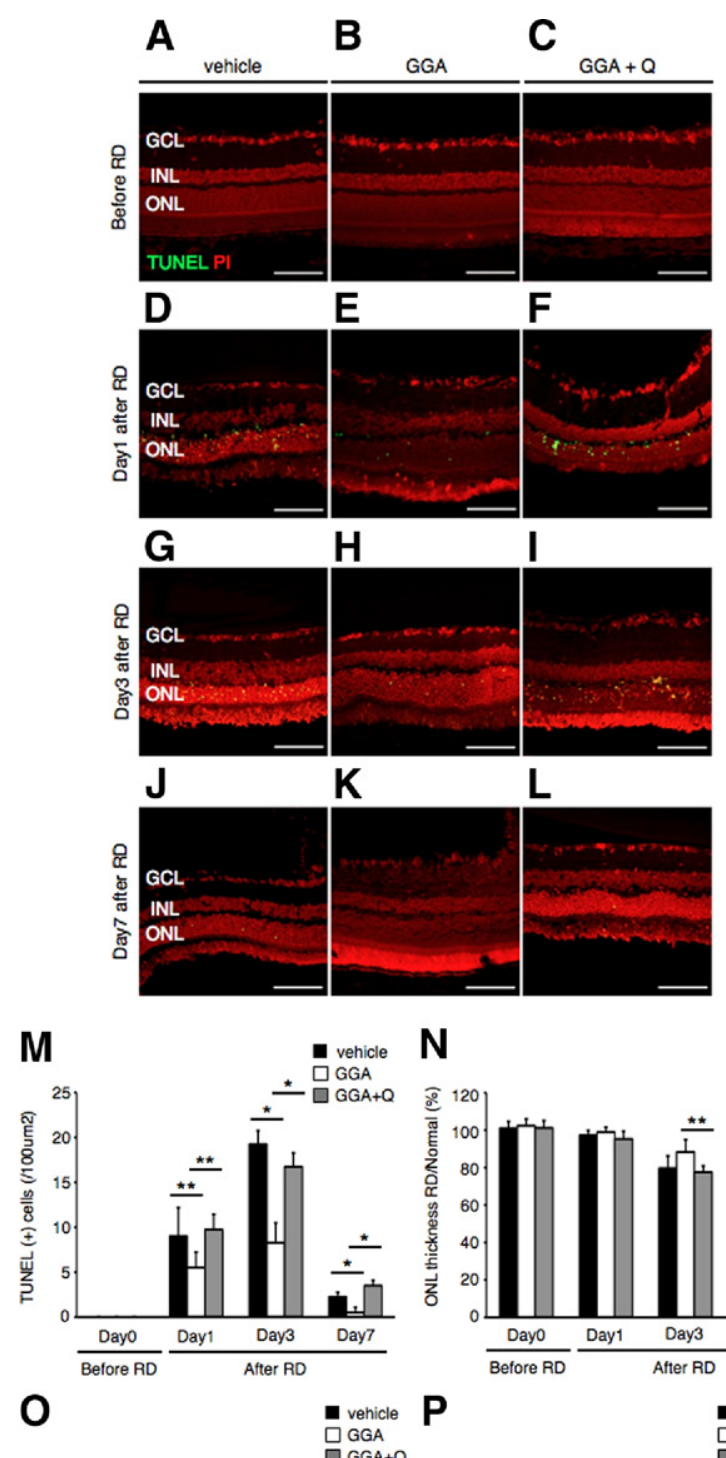

a vehicle
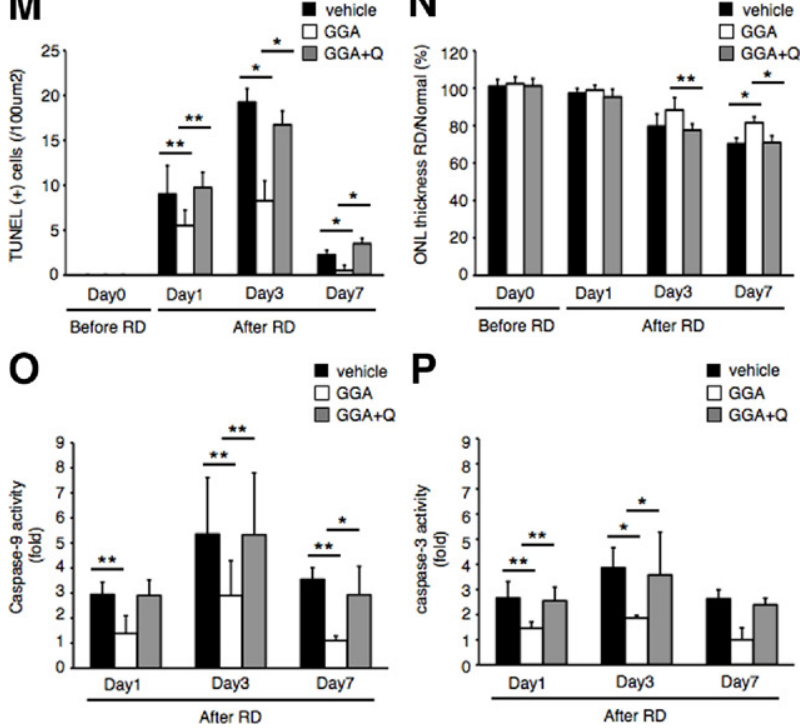

Figure 6. Protection of photoreceptor apoptosis by administration of geranylgeranylacetone (GGA). TUNEL assay in the vehicle (A, D, G, J), GGA $(\mathbf{B}, \mathbf{E}, \mathbf{H}, \mathbf{K})$ and GGA with quercetin $(\mathbf{C}, \mathbf{F}, \mathbf{I}, \mathbf{L}) 0,1,3$ and 7 days after RD. TUNEL $(+)$ cells were observed in the ONL. M: Quantification of transferasemediated dUTP nick-end labeling (TUNEL) $(+)$ cells by immunohistochemistry. Note that the number of TUNEL $(+)$ cells was significantly lower in the GGA than in the vehicle or GGA with quercetin $\left({ }^{*} P<0.01\right.$ $\left.{ }_{* * *} P<0.05\right)$. N: Relative ratio of the outer nuclear layer (ONL) thickness in each group. In the all groups, the ONL thickness was decreased with time. However, decrease of the ONL thickness in the GGA group was significantly suppressed compared with another two groups of them $\left({ }^{*} P<0.01 ;{ }^{* *} P<\right.$ $0.05)$. O: Suppression of caspase-9 activity after retinal detachment (RD) by the administration of GGA at the time point of RD in the compared with vehicle or GGA with quercetin groups ( $\left.{ }^{*} P<0.01 ;{ }^{* *} P<0.05\right)$. P: Suppression of caspase- 3 activity after RD by the administration of GGA at the time point of RD in the compared with vehicle or GGA with quercetin groups $\left.{ }^{*} P<0.01 ;{ }^{* *} P<0.05\right)$. Each column represents the mean $\pm \mathrm{SD}$ of six independent experiments. Scale bars $=100 \mathrm{um}$. Q, quercetin; GCL, retinal ganglion cell layer; INL, inner nuclear layer; ONL, outer nuclear layer. 
A

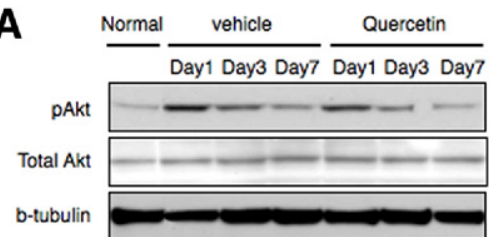

D

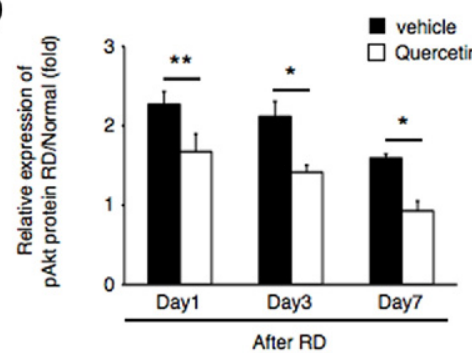

B

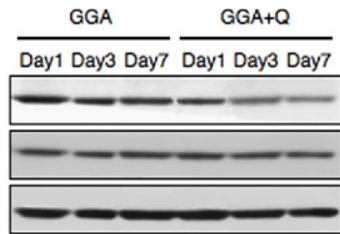

E

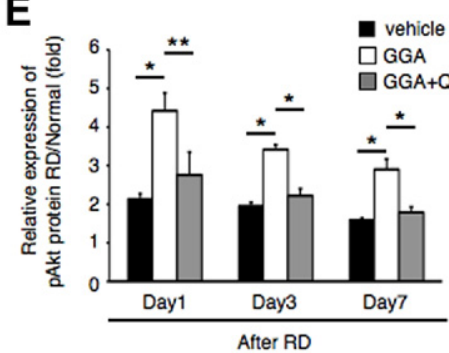

C

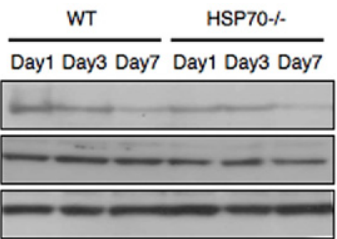

$\mathbf{F}$

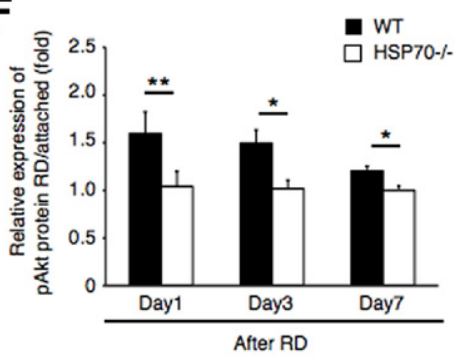

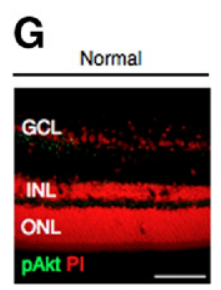

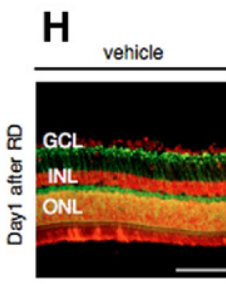

I Quercetin

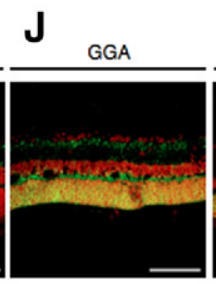

$\mathbf{K}_{\mathrm{GGA}+\mathrm{Q}}$

$L_{\text {HSP70-1. }}$
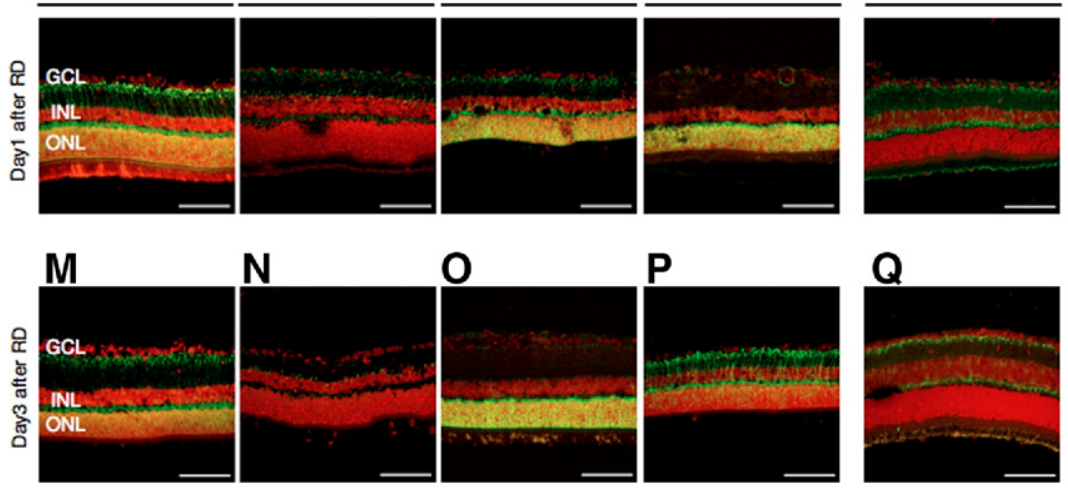

Figure 7. HSP70 induce Akt activation after retinal detachment (RD). A-C: Western blot analyses show the dynamics of protein expression of phosphorylated Akt (pAkt) and total Akt in each group. D-F: Relative protein expression ratio of pAkt 1, 3, and 7 days after RD in each group. The expression protein of pAkt was normalized by the normal group (attached retina). Activation of Akt was suppressed with time-dependent manner $\left({ }^{*} P<0.01\right.$; ${ }^{* *} P<0.05$ ). Equal quantities of protein were loaded in all lanes, and representative exposures of enhanced chemiluminescence detection of the immunoreactive proteins are shown. Each column represents the mean \pm SD of four independent experiments. G-Q: Immunofluorescent analysis for pAkt in retina of normal, vehicle, quercetin, geranylgeranylacetone (GGA), GGA with quercetin, and $\mathrm{HSP}^{-}-$mice groups at 1 and 3 days after RD. In the normal (attached retina), pAkt were rarely expressed in the whole layer. In the vehicle group, expression of pAkt was observed in the retinal ganglion cell layer (GCL) and outer nuclear layer (ONL). In the quercetin and $\mathrm{HSP}^{-/-}$mice group, pAkt were faintly expressed in the GCL at day 1; however, expression pattern was similar to the normal group at day 3. In the GGA group, expression of pAkt was remarkably observed in the GCL and ONL. On the other hand, expression of pAkt was similar to vehicle in the GGA with quercetin (Q). Each column represents the mean $\pm \mathrm{SD}$ of four independent experiments. Scale bars $=100 \mathrm{um}$. INL, inner nuclear layer; WT, wild type.

\section{RD Promotes HSP70 Association with Phosphorylated Akt}

Because HSP70 is known to modulate Akt kinase activity, we further investigated whether Akt activation in RD was mediated through HSP70. To this aim, we performed immunoprecipitation with an antibody against pAkt and immunoblotted with an anti-HSP70 antibody. In our coimmunoprecipitation assay, direct interaction between pAkt and HSP70 was observed after RD (Figure 8A). However, this interaction was suppressed after quercetin administration (Figure 8, A and B) (vehicle, 2.6-fold; quercetin, 1.2-fold). These results show that after RD HSP70 associates with pAkt and quercetin treatment decreases pAkt-HSP70 interaction.

\section{Discussion}

Several reports in the past have identified the activation of cell death pathways as a mechanism of photoreceptor loss in $\mathrm{RD}$, yet little is known about counteracting pathways that promote photoreceptor survival. In this study, we provide compelling evidence that inducible HSP70 is critical for the photoreceptor stress response after RD. Moreover, RD activated the PI3K-Akt pro-survival pathway and HSP70 associated with phosphorylated Akt kinase modulating its anti-apoptotic activity (Figure $8 \mathrm{C}$ ). We believe this is the first report showing the pivotal role of inducible HSP70 in photoreceptor survival after RD.

In this study, RD induced immediate and significant gene expression of HSP70 that peaked at 1 day after RD and decreased thereafter time dependently (Figure 1). Abolishment of HSP70 induction, either with the use of quercetin or $\mathrm{HSP} 70^{-1-}$ mice, exacerbated photoreceptor apoptosis, as well as retinal degeneration after RD (Figures $2-4)$. These results are in accordance with previous in vitro and in vivo studies, which showed that abolishment of HSP70 cytoprotective effect augments the initiation of the apoptotic cascade. ${ }^{33,34}$ The important role of inducible HSP70 in the acute phase stress response after RD 
A

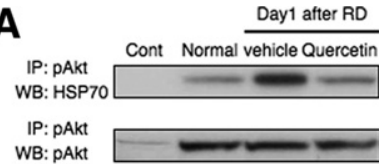

B

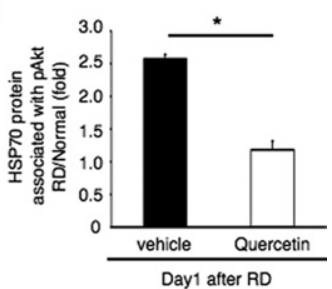

C

C Detached retina
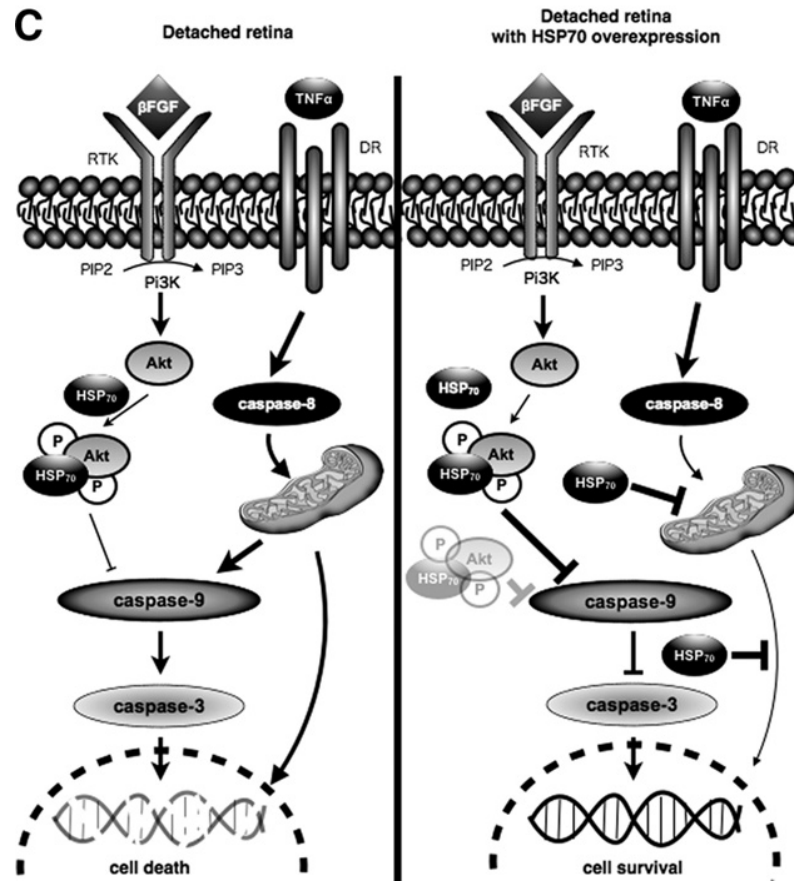

Figure 8. HSP70 association with phosphorylated Akt (pAkt). A and B Immunoprecipitation analysis of pAkt and HSP70. A: Extracted protein from each group at 1 day after retinal detachment (RD) were immunoprecipitated (IP) with anti-pAkt antibody or control rabbit IgG, followed by immunoblotting (WB). B: Relative protein expression ratio of pAkt and HSP70 at 1 day after RD in each group. There was a significant difference in HSP70 protein level between the vehicle and the quercetin groups $\left({ }^{*} P<0.01\right)$. pAkt signals did not differ among the normal, vehicle, and quercetin groups. Each column represents the mean \pm SD of four independent experiments. C: Schematic presentation of RD with and without HSP70 overexpression induced apoptosis pathways showing the position of the various intermediates being examined in this study. DR, death receptor; FGF, fibroblast growth factor; HSP $_{70}$, heat shock protein 70; TNF, tumor necrosis factor; $\mathrm{P}$, phosphorylated; Pi3K, phosphoinositide 3-kinase; PIP2, phosphatidylinositol-bisphophate; PIP3, phosphatidylinositol-trisphosphate; RTK, receptor tyrosine kinase

was also demonstrated by the fact that $\mathrm{HSP} 70^{-1-}$ mice exhibited three times more TUNEL $(+)$ cells day 1 after $\mathrm{RD}$ compared to mice pretreated with quercetin, whereas HSP70 induction was partially blocked (Figure 4G). It is possible that HSP70 up-regulation is able to inhibit the immediate initiation of apoptotic cascades at the acute phase of RD, given its diverse anti-apoptotic functions. Furthermore, we and others have previously established the involvement of both caspase-dependent and -independent pathways in photoreceptor cell death after $\mathrm{RD}^{8,35,36}$ and multiple reports have identified HSP70 as an endogenous inhibitor of many of the molecules involved in those pathways. ${ }^{11,37,38}$ In the experimental RD model, HSP inhibition resulted in more numerous cleaved caspase-3 $(+)$ cells than cleaved caspase- $9(+)$ cells. Therefore, it is likely that both pathways contribute to the increase in photoreceptor apoptosis seen after HSP70 inhibition.

It is accepted that RD induces apoptosis in the ONL of the detached portion of the retina, because the physical separation precludes nutrient diffusion from the underlying choroidal blood supply to the photoreceptors. Interestingly, HSP70 deficient mice exhibited significant cell apoptosis in the retinal ganglion cell layer and inner nuclear layer after RD induction (Figure 4, B, D, and F), despite the fact that blood supply to these layers originates from the epi-retinal and intra-retinal vascular network. A plausible explanation is that HSP70 ablation increased the activity of the pro-apoptotic c-Jun N-terminal kinase, which has been reported to be inhibited endogenously by HSP70 and involved in retinal ganglion cell death. ${ }^{39,40}$ Furthermore, previous studies have demonstrated extensive neuronal damage in $\mathrm{HSP} 70^{-1-}$ mice after ischemic brain injury, in which the neuronal expression of HSP70 can be interpreted as a molecularly defined penumbra of protein denaturation. ${ }^{34}$ In the RD model, the same phenomenon may occur with a cell death penumbra beyond the injured site. However, the molecular mechanisms involved in this phenomenon warrant further investigation.

The most important novel finding of this study is that $\mathrm{RD}$ induces activation of the PI3K-Akt pathway, which is strongly associated with cellular survival. In fact, activation of Akt in some neuronal types leads to an inhibition of proteins central to the cell death machinery, such as the pro-apoptotic $\mathrm{Bcl}-2$ family member $\mathrm{Bcl}$-2-associated death promoter (BAD) ${ }^{41}$ and members of the caspase family. ${ }^{42,43}$ Maximal activation of Akt kinase was observed 1 day after $\mathrm{RD}$ and decreased thereafter in a time-dependent manner. The PI3K-Akt pathway is activated by a wide variety of growth factors, including fibroblast growth factor. ${ }^{44}$ The latter has been shown to be up-regulated 24 hours after $\mathrm{RD}$, thus being a plausible candidate for this effect. ${ }^{20}$ Furthermore, based on a recent report that HSP70 can modulate Akt kinase activity, ${ }^{15}$ we investigated the effect of HSP70 inhibition or overexpression on photoreceptor Akt activity after RD. Indeed, quercetin treatment decreased Akt activity and augmented photoreceptor apoptosis, whereas GGA administration prolonged Akt activity and ameliorated cell death, indicating a direct correlation between Akt activity status and photoreceptor survival. These data were further confirmed by our finding that HSP70 and pAkt strongly associated in the detached retina. Finally, the decreased phosphorylation status of Akt kinase in $\mathrm{HSP} \mathrm{O}^{-1-}$ mice after RD can partially explain the dramatic increase in photoreceptor cell death compared to wild-type controls. However, the quercetin and GGA are not a specific inhibitor or activator of HSP70. ${ }^{30,45}$ Therefore, we cannot precisely exclude the possibility of several other effects using both compounds.

In summary, the present study shows the multifaceted role of HSP70 in maintaining photoreceptor survival after $\mathrm{RD}$. We propose, in this experimental model, that HSP70 up-regulation prevents photoreceptors from undergoing immediate apoptosis by directly interacting with phosphorylated Akt kinase, preventing its dephosphorylation 
and further inhibiting the activation of apoptotic pathways. Our data provide important insights regarding the role of HSP70 in the molecular interplay between prosurvival and pro-apoptotic pathways occurring after various retinal diseases induced RD and suggest it as a potential target for pharmacological treatment.

\section{References}

1. Dunaief $\mathrm{JL}$, Dentchev T, Ying GS, Milam AH: The role of apoptosis in age-related macular degeneration. Arch Ophthalmol 2002, 120: 1435-1442

2. Barber AJ, Lieth E, Khin SA, Antonetti DA, Buchanan AG, Gardner TW: Neural apoptosis in the retina during experimental and human diabetes. Early onset and effect of insulin J Clin Invest 1998, 102: 783-791

3. Fulton AB, Hansen RM, Petersen RA, Vanderveen DK: The rod photoreceptors in retinopathy of prematurity: an electroretinographic study. Arch Ophthalmol 2001, 119:499-505

4. Williams GA, Aaberg TM: Techniques of scleral buckling. Retina, vol 3: Surgical retina, ed 3. Edited by Ryan SJ. St. Louis, Mosby, 2001, pp 2010-2046

5. Zacks DN, Han $Y$, Zeng $Y$, Swaroop A: Activation of signaling pathways and stress response genes in an experimental model of retinal detachment. Invest Ophthalmol Vis Sci 2006, 47:1691-1695

6. Hassan TS, Sarrafizadeh R, Ruby AJ, Garretson BR, Kuczynski B, Williams GA: The effect of duration of macular detachment on results after the scleral buckle repair of primary, macula-off retinal detachments. Ophthalmology 2002, 109:146-152

7. Hisatomi T, Sakamoto T, Goto Y, Yamanaka I, Oshima Y, Hata Y, Ishibashi T, Inomata H, Susin SA, Kroemer G: Critical role of photoreceptor apoptosis in functional damage after retinal detachment. Curr Eye Res 2002, 24:161-172

8. Zacks DN, Hänninen V, Pantcheva M, Ezra E, Grosskreutz C, Miller JW: Caspase activation in an experimental model of retinal detachment. Invest Ophthalmol Vis Sci 2003, 44:1262-1267

9. Nakazawa T, Hisatomi T, Nakazawa C, Noda K, Maruyama K, She H, Matsubara A, Miyahara S, Nakao S, Yin Y, Benowitz L, Hafezi-Moghadam A, Miller JW: Monocyte chemoattractant protein 1 mediates retinal detachment-induced photoreceptor apoptosis. Proc Natl Acad Sci USA 2007, 104:2425-2430

10. Snoeckx LH, Cornelussen RN, Van Nieuwenhoven FA, Reneman RS, Van Der Vusse GJ: Heat shock proteins and cardiovascular pathophysiology. Physiol Rev 2001, 81:1461-1497

11. Beere HM, Wolf BB, Cain K, Mosser DD, Mahboubi A, Kuwana T, Tailor P, Morimoto RI, Cohen GM, Green DR: Heat-shock protein 70 inhibits apoptosis by preventing recruitment of procaspase- 9 to the Apaf-1 apoptosome. Nat Cell Biol 2000, 2:469-475

12. Li Y, Roth S, Laser M, Ma JX, Crosson CE: Retinal preconditioning and the induction of heat-shock protein 27. Invest Ophthalmol Vis Sci 2003, 44:1299-1304

13. Kamradt MC, Lu M, Werner ME, Kwan T, Chen F, Strohecker A, Oshita S, Wilkinson JC, Yu C, Oliver PG, Duckett CS, Buchsbaum DJ, LoBuglio AF, Jordan VC, Cryns VL: The small heat shock protein alpha B-crystallin is a novel inhibitor of TRAIL-induced apoptosis that suppresses the activation of caspase-3. J Biol Chem 2005, 280: 11059-11066

14. Kitamei H, Kitaichi N, Yoshida K, Nakai A, Fujimoto M, Kitamura M, Iwabuchi K, Miyazaki A, Namba K, Ohno S, Onoé K: Association of heat shock protein 70 induction and the amelioration of experimental autoimmune uveoretinitis in mice. Immunobiology 2007, 212:11-18

15. Koren J 3rd, Jinwal UK, Jin Y, O'Leary J, Jones JR, Johnson AG, Blair LJ, Abisambra JF, Chang L, Miyata Y, Cheng AM, Guo J, Cheng JQ, Gestwicki JE, Dickey CA: Facilitating Akt clearance via manipulation of Hsp70 activity and levels. J Biol Chem 2010, 285:2498-2505

16. Gao T, Newton AC: The turn motif is a phosphorylation switch that regulates the binding of Hsp70 to protein kinase C. J Biol Chem 2002, 277:31585-31592

17. Sato S, Fujita N, Tsuruo T: Involvement of 3-phosphoinositide-dependent protein kinase- 1 in the MEK/MAPK signal transduction pathway. J Biol Chem 2004, 279:33759-33767
18. Ishii Y, Kwong JM, Caprioli J: Retinal ganglion cell protection with geranylgeranylacetone, a heat shock protein inducer, in a rat glaucoma model. Invest Ophthalmol Vis Sci 2003, 44:1982-1992

19. Kuo CC, Liang SM, Liang CM: CpG-B oligodeoxynucleotide promotes cell survival via up-regulation of $\mathrm{Hsp} 70$ to increase $\mathrm{Bcl}-\mathrm{xL}$ and to decrease apoptosis-inducing factor translocation. J Biol Chem 2006, 281:38200-38207

20. Nakazawa T, Matsubara A, Noda K, Hisatomi T, She H, Skondra D, Miyahara S, Sobrin L, Thomas KL, Chen DF, Grosskreutz CL, HafeziMoghadam A, Miller JW: Characterization of cytokine responses to retinal detachment in rats. Mol Vis 2006, 12:867-878

21. Huang W, Dobberfuhl A, Filippopoulos T, Ingelsson M, Fileta JB, Poulin NR, Grosskreutz CL: Transcriptional up-regulation and activation of initiating caspases in experimental glaucoma. Am J Pathol 2005, 167:673-681

22. Kayama M, Kurokawa M, Ueda $Y$, Ueno H, Kumagai $Y$, Chiba $S$, Takada E, Ueno S. Tadokoro M, Suzuki N: Transfection with Pax6 gene of mouse ES cells and subsequent cell cloning induced retinal neuron progenitors, including retinal ganglion cell-like cells, in vitro. Ophthalmic Res 2009, 43:79-91

23. Dean DO, Kent CR, Tytell M: Constitutive and inducible heat shock protein 70 immunoreactivity in the normal rat eye. Invest Ophthalmo Vis Sci 1999, 40:2952-2962

24. Yang L, Bula D, Arroyo JG, Chen DF: Preventing retinal detachmentassociated photoreceptor cell loss in Bax-deficient mice. Invest Ophthalmol Vis Sci 2004, 45:648-654

25. Arroyo JG, Yang L, Bula D, Chen DF: Photoreceptor apoptosis in human retinal detachment. Am J Ophthalmol 2005, 139:605-610

26. Kroemer G, Galluzzi L, Vandenabeele P. Abrams J, Alnemri ES, Baehrecke EH, Blagosklonny MV, El-Deiry WS, Golstein P, Green DR, Hengartner M, Knight RA, Kumar S, Lipton SA, Malorni W, Nuñez G, Peter ME, Tschopp J, Yuan J, Piacentini M, Zhivotovsky B, Melino G: Nomenclature Committee on Cell Death 2009: Classification of cell death: recommendations of the Nomenclature Committee on Cell Death 2009. Cell Death Differ 2009, 16:3-11

27. Bredesen DE, Rao RV, Mehlen P: Cell death in the nervous system. Nature 2006, 443:796-802

28. Hirakawa T, Rokutan K, Nikawa T, Kishi K: Geranylgeranylacetone induces heat shock proteins in cultured guinea pig gastric mucosal cells and rat gastric mucosa. Gastroenterology 1996, 111:345-357

29. Tsuruma T, Yagihashi A, Watanabe N, Yajima T, Kameshima H, Araya J, Hirata K: Heat-shock protein-73 protects against small intestinal warm ischemia-reperfusion injury in the rat. Surgery 1999, 125:385-395

30. Ooie T, Takahashi N, Saikawa T, Nawata T, Arikawa M, Yamanaka K, Hara M, Shimada T, Sakata T: Single oral dose of geranylgeranylacetone induces heat-shock protein 72 and renders protection against ischemia/ reperfusion injury in rat heart. Circulation 2001, 104:1837-1843

31. Cardone MH, Roy N, Stennicke HR, Salvesen GS, Franke TF, Stanbridge E, Frisch S, Reed JC: Regulation of cell death protease caspase-9 by phosphorylation. Science 1998, 282:1318-1321

32. Andjelković M, Alessi DR, Meier R, Fernandez A, Lamb NJ, Frech M, Cron P, Cohen P, Lucocq JM, Hemmings BA: Role of translocation in the activation and function of protein kinase B. J Biol Chem 1997 272:31515-31524

33. Spencer JP, Rice-Evans C, Williams RJ: Modulation of pro-survival Akt/protein kinase $B$ and ERK $1 / 2$ signaling cascades by quercetin and its in vivo metabolites underlie their action on neuronal viability. J Biol Chem 2003, 278:34783-34793

34. Lee SH, Kwon HM, Kim YJ, Lee KM, Kim M, Yoon BW: Effects of hsp70.1 gene knockout on the mitochondrial apoptotic pathway after focal cerebral ischemia. Stroke 2004, 35:2195-2199

35. Hisatomi T, Sakamoto T, Murata T, Yamanaka I, Oshima Y, Hata Y, Ishibashi T, Inomata H, Susin SA, Kroemer G: Relocalization of apoptosis-inducing factor in photoreceptor apoptosis induced by retinal detachment in vivo. Am J Pathol 2001, 158:1271-1278

36. Hisatomi T, Nakazawa T, Noda K, Almulki L, Miyahara S, Nakao S, Ito Y, She H, Kohno R, Michaud N, Ishibashi T, Hafezi-Moghadam A, Badley AD, Kroemer G, Miller JW: HIV protease inhibitors provide neuroprotection through inhibition of mitochondrial apoptosis in mice. $\mathrm{J}$ Clin Invest 2008, 118:2025-2038

37. Ravagnan L, Gurbuxani S, Susin SA, Maisse C, Daugas E, Zamzami N, Mak T, Jäättelä M, Penninger JM, Garrido C, Kroemer G: Heatshock protein 70 antagonizes apoptosis-inducing factor. Nat Cell Biol 2001, 3:839-843 
38. Matsumori Y, Hong SM, Aoyama K, Fan Y, Kayama T, Sheldon RA, Vexler ZS, Ferriero DM, Weinstein PR, Liu J: HSP70 overexpression sequesters AIF and reduces neonatal hypoxic/ischemic brain injury. J Cereb Blood Flow Metab 2005, 25:899-910

39. Park HS, Lee JS, Huh SH, Seo JS, Choi EJ: Hsp72 functions as a natural inhibitory protein of C-Jun N-terminal kinase. EMBO J 2001, 20:446-456

40. Kwong JM, Caprioli J: Expression of phosphorylated C-Jun N-terminal protein kinase (JNK) in experimental glaucoma in rats. Exp Eye Res 2006, 82:576-582

41. Zha J, Harada H, Yang E, Jockel J, Korsmeyer SJ: Serine phosphorylation of death agonist BAD in response to survival factor results in binding to 14-3-3 not BCL-X(L). Cell 1996, 87:619-628
42. Bonni A, Brunet A, West AE, Datta SR, Takasu MA, Greenberg ME: Cell survival promoted by the Ras-MAPK signaling pathway by transcription-dependent and -independent mechanisms. Science 1999 286:1358-1362

43. Datta SR, Brunet A, Greenberg ME: Cellular survival: a play in three Akts. Genes Dev 1999, 13:2905-2927

44. Chen GJ, Weylie B, Hu C, Zhu J, Forough R: FGFR1/PI3K/AKT signaling pathway is a novel target for antiangiogenic effects of the cancer drug fumagillin (TNP-470). J Cell Biochem 2007, 101:1492-1504

45. Hosokawa N, Hirayoshi K, Kudo H, Takechi H, Aoike A, Kawai K, Nagata K: Inhibition of the activation of heat shock factor in vivo and in vitro by flavonoids. Mol Cell Biol 1992, 12:3490-3498 